EDITOR'S

CHOICE
- Additional methods, figures and a table are published online only. To view these files please visit the journal online (http:// gut.bmj.com)

${ }^{1}$ Department of Medicine, Duke University, Durham, North Carolina, USA

${ }^{2}$ Department of Pathology, Duke University, Durham, North

Carolina, USA

\section{Correspondence to}

Professor Anna Mae Diehl, Division of Gastroenterology, Duke University, Snyderman Building (GSRB-1), 595 LaSalle Street, Suite 1073, Durham, NC 27710, USA:

annamae.diehl@mc.duke.edu

Revised 11 February 2010 Accepted 11 February 2010

\title{
Signals from dying hepatocytes trigger growth of liver progenitors
}

\author{
Youngmi Jung, ${ }^{1}$ Rafal P Witek, ${ }^{1}$ Wing-Kin Syn, ${ }^{1}$ Steve S Choi, ${ }^{1}$ Alessia Omenetti, \\ Richard Premont, ${ }^{1}$ Cynthia D Guy, ${ }^{2}$ Anna Mae Diehl ${ }^{1}$
}

\section{ABSTRACT}

Objective The death rate of mature hepatocytes is chronically increased in various liver diseases, triggering responses that prevent liver atrophy, but often cause fibrosis. Mice with targeted disruption of inhibitor kappa B kinase (lkk) in hepatocytes ( $\triangle \mathrm{HEP}$ mice) provide a model to investigate this process because inhibiting

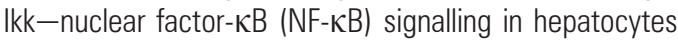
increases their apoptosis.

Methods Cell proliferation, apoptosis, progenitors, fibrosis and production of Hedgehog (Hh) ligands (progenitor and myofibroblast growth factors) were compared in $\triangle$ HEP and control mice before and after feeding methionine choline-deficient ethioninesupplemented (MCDE) diets. Ikk $\beta$ was deleted from primary hepatocytes to determine the effects on $\mathrm{Hh}$ ligand production; Hh signalling was inhibited directly in progenitors to determine the effects on viability. Liver sections from patients were examined to assess relationships between hepatocyte production of $\mathrm{Hh}$ ligands, accumulation of myofibroblastic cells and liver fibrosis.

Results Disrupting the Ikk-NF- $\kappa B$ pathway in hepatocytes inhibited their proliferation but induced their production of $\mathrm{Hh}$ ligands. The latter provided viability signals for progenitors and myofibroblasts, enhancing accumulation of these cell types and causing fibrogenesis. Findings in the mouse models were recapitulated in diseased human livers.

Conclusion Dying mature hepatocytes produce $\mathrm{Hh}$ ligands which promote the compensatory outgrowth of progenitors and myofibroblasts. These results help to explain why diseases that chronically increase hepatocyte death promote cirrhosis.

\section{INTRODUCTION}

Repetitive exposure to various insults chronically increases the death rate of mature hepatocytes and triggers reparative responses to reconstitute damaged hepatic epithelium. Chronic liver injury is often accompanied by progressive liver fibrosis. ${ }^{1}$ However, it is not fully understood why situations that cause chronic, but relatively incremental, increases in the rate of mature hepatocyte death typically result in some degree of hepatic architectural distortion and tend to promote liver fibrosis, when such outcomes rarely complicate recovery from acute injuries that abruptly cause massive hepatocyte loss. ${ }^{2}$

In order to investigate regenerative mechanisms associated with chronically increased rates of hepatocyte death, we took advantage of mice with targeted disruption of the kinase that promotes nuclear accumulation of nuclear factor- $\kappa \mathrm{B}(\mathrm{NF}-\kappa \mathrm{B})$,

\section{Significance of this study}

What is already known about this subject?

- Disruption of the $1 \mathrm{kk} \beta$ kinase, and other factors that inhibit nuclear localisation of the prosurvival transcription factor NF-KB, promote the death of mature hepatocytes.

- The death rate of hepatocytes is increased chronically in many types of chronic hepatitis, including non-alcoholic steatohepatitis (NASH).

- Chronic efforts to regenerate dead hepatocytes are often associated with liver fibrosis.

- Chronic regenerative responses also increase the risk of liver cancer.

\section{What are the new findings?}

- Dying hepatocytes generate Hedgehog (Hh) ligands, but are not $\mathrm{Hh}$ responsive themselves.

- Hh ligands are viability factors for liver progenitors, and thus promote hepatic accumulation of cells that might contribute to cancer formation.

- Hh ligands also promote hepatic accumulation of myofibroblasts, and thus increase fibrogenesis.

How might they impact on clinical practice in the foreseeable future?

- Non-invasive tests that detect/quantify $\mathrm{Hh}$ pathway activity might provide novel biomarkers of fibrogenesis and cancer risk in NASH.

- Hh inhibitors might reduce development of cirrhosis and liver cancer by removing viability signals for myofibroblasts and immature liver cells.

a transcription factor that controls expression of genes that encode hepatocyte viability factors. $\mathrm{NF}-\kappa \mathrm{B}$ is held in the cytoplasm in its inactive form by a specific inhibitor, inhibitor $\kappa \mathrm{B}(\mathrm{I} \kappa \mathrm{B})$. The $\mathrm{I} \kappa \mathrm{B}$ kinase (Ikk) complex phosphorylates I $\kappa \mathrm{B}$, allowing $\mathrm{NF}-\kappa \mathrm{B}$ to translocate into the nucleus. ${ }^{3} \mathrm{Ikk}$ is comprised of three subunits, Ikk $\alpha, \operatorname{Ikk} \beta$ and Ikk $\gamma$. Hepatocyte-specific deletion of $\operatorname{Ikk} \beta$ inhibits nuclear localisation of NF- $\kappa B$, reduces expression of hepatocyte viability factors and increases hepatocyte susceptibility to apoptosis. ${ }^{4-6}$

The present study evaluates the hypothesis that hepatocytes that are prone to apoptosis have an impaired proliferative capacity, but elaborate paracrine signals that trigger compensatory growth of 
progenitors which ultimately regenerate the hepatic parenchyma. Further, we theorise that this process also promotes hepatic fibrogenesis. Hedgehog $(\mathrm{Hh})$ ligands activate a morphogenic signalling pathway that orchestrates tissue construction during development and adult wound healing. Because $\mathrm{Hh}$ pathway activity is low in healthy livers but high in various types of diseased livers, and Hh signalling promotes the growth of liver progenitors and myofibroblasts, ${ }^{7} 8$ our aims were to determine if, and how, disrupting NF- $\mathrm{BB}$ survival signals in hepatocytes activates the $\mathrm{Hh}$ pathway in other liver cell types that are involved in fibrogenic repair of damaged livers. The results confirm our hypothesis and demonstrate an unsuspected mechanism that couples hepatocyte death to regenerative strategies that result in fibrogenic repair of liver damage.

\section{MATERIAL AND METHODS}

\section{Experimental animals}

Ikk $\beta^{\mathrm{F} / \mathrm{F}}$ and Ikk $\beta^{\Delta \mathrm{Hep}}$ mice were generous gifts from Dr Michael Karin (University of California San Diego). $\operatorname{Ikk} \beta^{\mathrm{F} / \mathrm{F}}$ mice were bred with Alb-Cre mice to generate mice in which all albuminexpressing cells (eg, hepatocytes) and their progeny are Ikk $\beta$ deficient (referred to as $\operatorname{Ikk} \beta^{\Delta \mathrm{Hep}}$ ). All mice were housed in a facility with a $12 \mathrm{~h}$ light/dark cycle and allowed free access to food and water. Adult mice were used between 5 and 8 months of age. To induce oxidative liver injury, inhibit replication of mature hepatocytes and activate hepatic stellate cells (HSCs) and liver progenitor populations, $\operatorname{Ikk} \beta^{\mathrm{F} / \mathrm{F}}(\mathrm{n}=7)$ and $\operatorname{Ikk} \beta^{\Delta \mathrm{Hep}}$ mice $(n=9)$ were fed a methionine/choline-deficient diet supplemented with $0.15 \%$ ethionine (MCDE). Surviving mice were sacrificed after being fed MCDE diets for 1 week ( $\mathrm{Ikk}^{\mathrm{F} / \mathrm{F}}$ mice $\left.n=7 ; I_{k}{ }^{\Delta H e p} n=5\right)$. Chow-fed Ikk $\beta^{F / F}(n=6)$ and Ikk $\beta^{\Delta H e p}$ mice $(n=6)$ were also sacrificed at the same time point.

Animal care and surgical procedures were approved by the Duke University Medical Center Institutional Animal Care and Use Committee as set forth in the 'Guide for the Care and Use of Laboratory Animals' published by the National Institutes of Health.

\section{Human subjects}

Anomymised liver biopsy-proven non-alcoholic steatohepatitis (NASH) $(n=5)$ and NASH-related cirrhosis $(n=6)$ specimens were obtained from the Duke University, Division of Gastroenterology and Department of Pathology. The control liver tissues were obtained from the Duke University School of Medicine Tissue Bank Shared Resource and studied in accordance with NIH and Institutional guidelines for human subject research.

\section{Liver histology and immunohistochemistry}

Specimens fixed in formalin and embedded in paraffin were cut into $4 \mu \mathrm{m}$ sections, dewaxed, hydrated, and subsequently incubated for $10 \mathrm{~min}$ in $3 \%$ hydrogen peroxide to block endogenous peroxidase. Antigen retrieval was performed by heating in $10 \mathrm{mM}$ sodium citrate buffer ( $\mathrm{pH}$ 6.0) for 10 min or incubation with $0.25 \%$ pepsin for $10 \mathrm{~min}$. Sections were blocked in Dako protein block (X9090; Dako Envision, Dako, USA) for $30 \mathrm{~min}$ and incubated with primary antibodies, active capase 3 (9661, 1:250; Cell Signaling, Danvers, Massachusetts, USA), Ki67 (NCL-Ki67, 1:1000, Novocastra, Leica Microsystems, Newcastle Upon Tyne, UK), AE1/AE3 (18-0132, 1:500; Invitrogen, Carlsbad, California, USA), A6 (a gift from Dr Valentina Factor, National Institutes of Health, Bethesda, Maryland, USA), NF-אB p65 (ab7970, 1:5000; Abcam, Cambridge, Massachusetts, USA), Gli2 (26056, 1:4500; Abcam) and Sonic hedgehog (Shh; 1843-1, 1:7500; Epitomics, Burlingame, CA) at $4^{\circ} \mathrm{C}$ overnight. Other sections were also incubated at $4^{\circ} \mathrm{C}$ overnight in non-immune sera. Polymer- horseradish peroxidase (HRP) antirabbit (K4003; Dako), antimouse (K4001; Dako) or MACH3 mouse AP polymer kit (MP530, Biocare Medical, Concord, California, USA) was used as secondary antibody. 3,3'-Diaminobenzidine (DAB) was employed in the detection procedure. Omitting primary antibodies from the reactions eliminated staining, demonstrating staining specificity.

Sirius red staining and AE1/AE3 and A6 immunohistochemical staining were assessed by morphometry (MetaView software, Universal Imaging Corp, Downington, Pennsylvania, USA). To quantify Sirius red staining, 10 randomly chosen $20 \times$ fields/section were evaluated for each mouse. The quantification of AE1/AE3 and A6 staining was evaluated by randomly choosing eight portal tracts (PTs) excluding the major bile duct, at $40 \times$ fields/section for each mouse. After excluding the major bile duct in each PT from consideration, cells staining positively for Ki67, p65 (cytosol or nuclear) or Gli2 (a Hh-regulated transcription factor) in eight $\mathrm{PTs} /$ slide were counted at $\times 40$ magnification. PTs selected for analysis contained a portal vein that ranged from 120 to $180 \mu \mathrm{m}$. The average number of Ki67- or Gli2-positive ductular cells was obtained by dividing the total number of positive cells by the total number of PTs. Ki67-, p65or Gli2-positive hepatocytes were quantified by counting the total number of Ki67-, p65- or Gli-positive hepatocytes/field and dividing by the total number of hepatocytes/field.

\section{RNA and protein analysis}

Total RNA and protein were extracted from freeze-clamped liver samples that had been stored at $-80^{\circ} \mathrm{C}$. A detailed protocol and the antibodies used are listed in the Supplementary Materials and methods. The sequences of primers for mice are summarised in Supplementary table 1.

\section{Hepatic hydroxyproline assay}

The hydroxyproline content in whole liver specimens was quantified colourimetrically as described in the Supplementary Materials and methods.

\section{Isolation and study of primary liver cells from mice}

Primary hepatocytes were obtained as described. ${ }^{6} 9$ To isolate primary liver progenitors, we performed a two-step collagenase perfusion according to the protocol of Selgen et $a{ }^{10},{ }^{10}$ and collected the non-parenchymal cell (NPC) fraction that contained progenitors using gradient centrifugation. Isolated cells were incubated with anti-Sca (stem cell antigen)-1 fluorescein isothiocyanate (FITC)conjugated antibody (130-092-529 MACs, Miltenyi Biotec. GmbH, Bergisch Gladbach, Germany), followed by anti-FITC microbeads. After incubation, cells were positively selected using a MACS (magnetic-activated cell separation) sort. ${ }^{11}{ }^{12}$ As determined by trypan blue exclusion, cell viability was $>90 \%$ in all experiments.

To evaluate apoptotic activity, hepatocytes and progenitors were cultured for $24 \mathrm{~h}$ and then cytocentrifuged to slides and examined for annexin V (ab14196, Abcam). For double immunofluorescent staining, cytospun cells were fixed, permeabilised, and processed for immunostaining with primary antibody annexin V and albumin (MAB1455, 1:100; R\&D Systems, Minneapolis, Minnesota, USA). Alexa Fluor 568 and Alexa Fluor 488 (Molecular Probes, Eugene, Oregon, USA) were used as secondary antibodies. 4',6-Diamidino-2-phenylindole (DAPI) counterstaining was employed to demonstrate nuclei. Hepatocytes were also labelled with anti-mouse CD26 (559652, BD Biosciences, San Jose, California, USA) and annexin V (559933, $\mathrm{BD}$ Biosciences) or matched isotype control antisera, and analysed using the FACS VantageSe (Beckton Dickinson, Franklin Lakes, New Jersey, USA). 
In separate experiments other freshly isolated progenitors were seeded in 96-well tissue culture plates (2000 cells/well) and grown in Iscove's modified Dulbecco's medium (IMDM) supplemented with $10 \%$ fetal bovine serum (FBS). After $72 \mathrm{~h}$, the medium was replaced with 1\% FBS IMDM; the next morning cells were treated with either cyclopamine $(3 \mu \mathrm{M}$, Toronto Research Chemicals, North York, Ontario, Canada) or tomatidine ( $3 \mu \mathrm{M}$, Calbiochem, San Diego, California, USA) for $24 \mathrm{~h}$. Control wells were treated with an equal volume of vehicle (dimethylsulfoxide (DMSO)) for the same treatment period. At the end of the treatment period, cell numbers were determined by Cell Counting Kit-8 (CCK-8, Dojindo, Rockvilee, Maryland, USA). A calibration curve was prepared using wells containing a fixed numbers of viable cells. A FLUOstar OPTIMA microplate reader (BMG Labtech, Durham, North Carolina, USA) was used for absorbance measurements.

Primary hepatocytes isolated from wild-type and $\operatorname{Ikk} \beta^{\mathrm{F} / \mathrm{F}}$ mice $(\mathrm{n}=5$ /group) were cultured in the presence of adenoviral vectors carrying green fluorescent protein (AdGFP) or Cre recombinanse (AdCre) (multiplicity of infection (MOI) 25). Cultures were analysed at 24 and $48 \mathrm{~h}$.

\section{Statistical analysis}

Results are expressed as the mean \pm SEM. Significance was established using the Student $t$ test and analysis of variance when appropriate. Differences were considered significant when $\mathrm{p}<0.05$.

\section{RESULTS}

Ikk $\beta^{\Delta H e p}$ mice have more apoptotic hepatocytes and increased liver progenitors

Although livers of $\operatorname{Ikk} \beta^{\Delta \text { Hep }}$ mice appeared grossly normal at baseline (Supplementary figure 1), they had increased caspase 3 activity by immunohistochemistry (IHC) (figure 1A, B) and western blot analysis (figure $1 \mathrm{C}$ ). IHC of primary hepatocytes that were double-stained for annexin V, a marker of cells
Figure 1 Increased hepatocyte apoptosis in Ikk $\beta^{\Delta \text { Hep }}$ mice. (A, B) Liver sections stained to demonstrate activated caspase 3 from representative $\mathrm{Ikk} \beta^{\mathrm{F} / \mathrm{F}}(\mathrm{A})$ and $\mathrm{lkk} \beta^{\Delta \mathrm{Hep}}(\mathrm{B})$ mice $(\times 40)$. (C) Western blot analysis for caspase 3 in whole liver extracts from $\mathrm{lkk} \beta^{\mathrm{F} / \mathrm{F}}$ and $\mathrm{lkk} \beta^{\Delta \mathrm{Hep}}$ mice ( $\mathrm{n}=3$ mice) group). Densitometric data are displayed as the mean \pm SD $\left({ }^{*} \mathrm{p}<0.05\right.$ vs the $I k k \beta^{F / F}$ group). (D1-4) Double immunoflorescent staining for albumin (green) and annexin V (red) in representative primary hepatocyte cytospins from Ikk $\beta^{\mathrm{F} / F}$ and Ikk $\beta^{\Delta \mathrm{Hep}}$ mice: albumin (green, D1), annexin V (red, D2) and merged image of albumin and annexin $V$ (yellow, D3) in hepatocytes from Ikk $\beta^{\Delta \mathrm{Hep}}$ mice. Arrows indicate the albumin and annexin V double-positive (yellow) hepatocytes which are magnified in D4. The inserted image in D3 shows the merged images of representative albumin/annexin V-stained hepatocytes from $l k k \beta^{F / F}$ mice $(\times 40)$. (E)

Representative fluorescence-activated cell sorting (FACS) analysis of primary hepatocytes from $\mathrm{lkk} \beta^{\mathrm{F} / F}$ and $\operatorname{lkk} \beta^{\Delta \mathrm{Hep}}$ mice. Cells were incubated with antibodies to CD26 and annexin V. (F) Graphic summary of FACS data $(n=4$ mice/group). Results are expressed as the mean \pm SD $\left(^{*} p<0.05\right.$ vs the $1 k k \beta^{F / F}$ group).
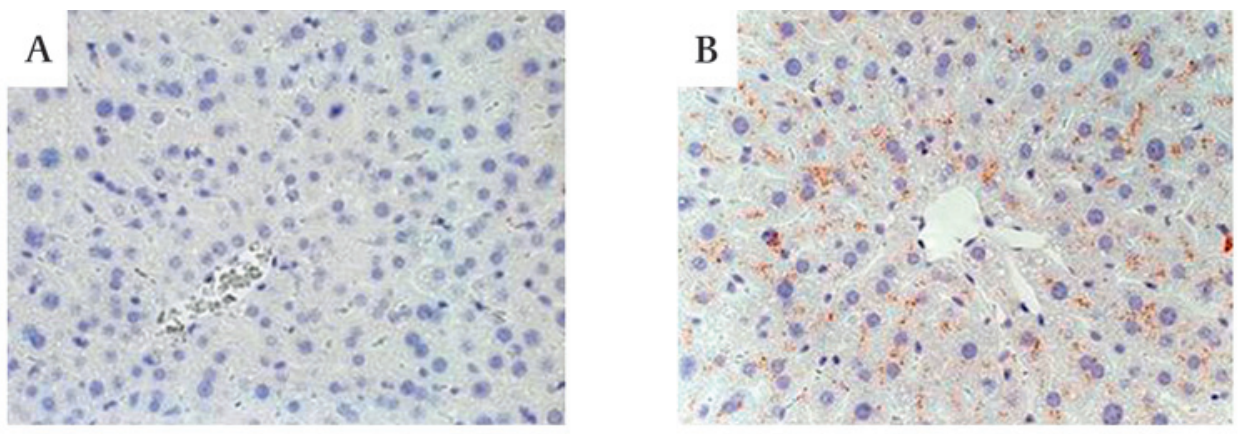

C

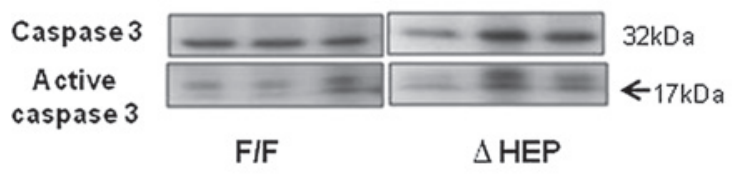

D
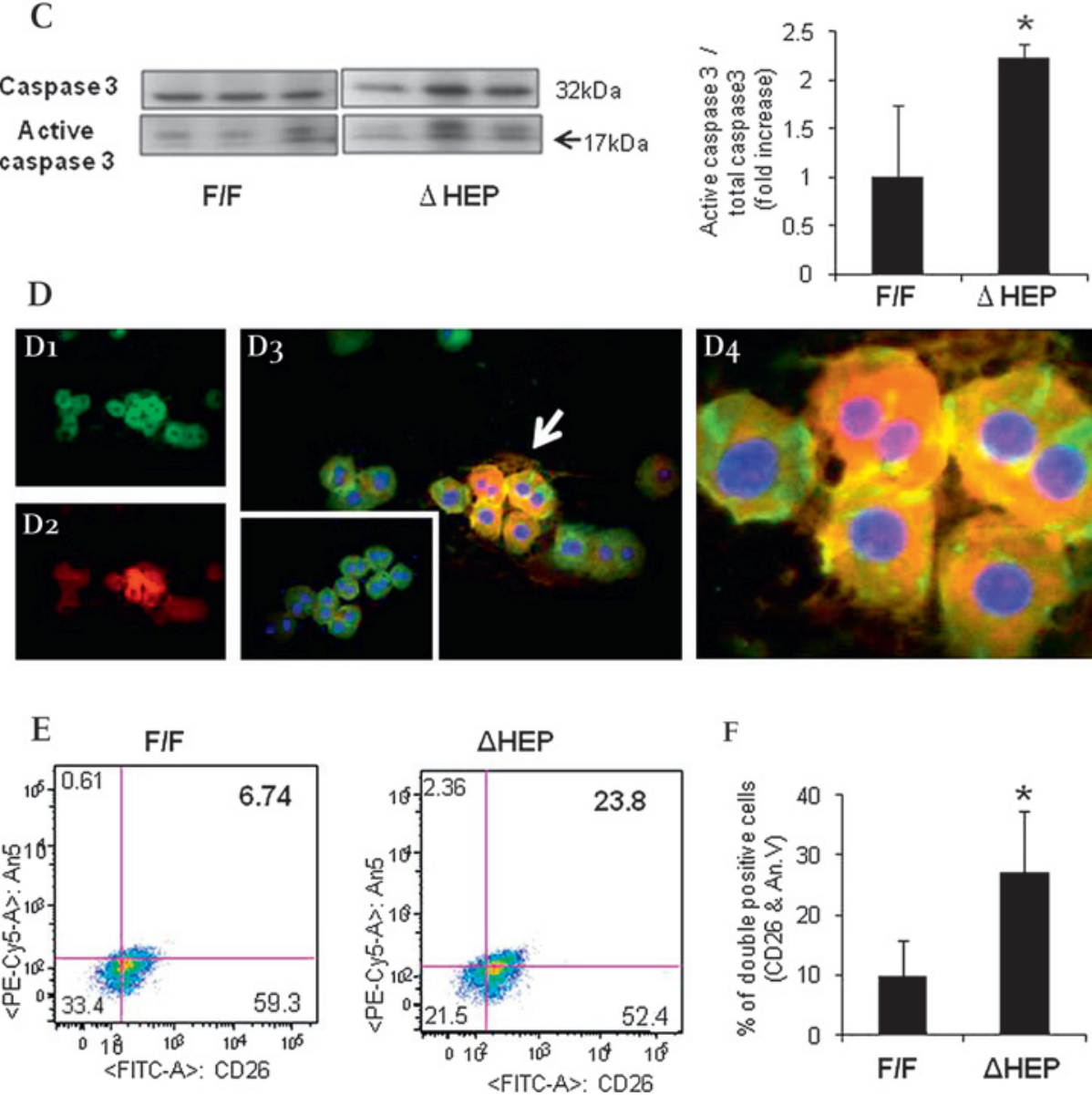


\section{A}

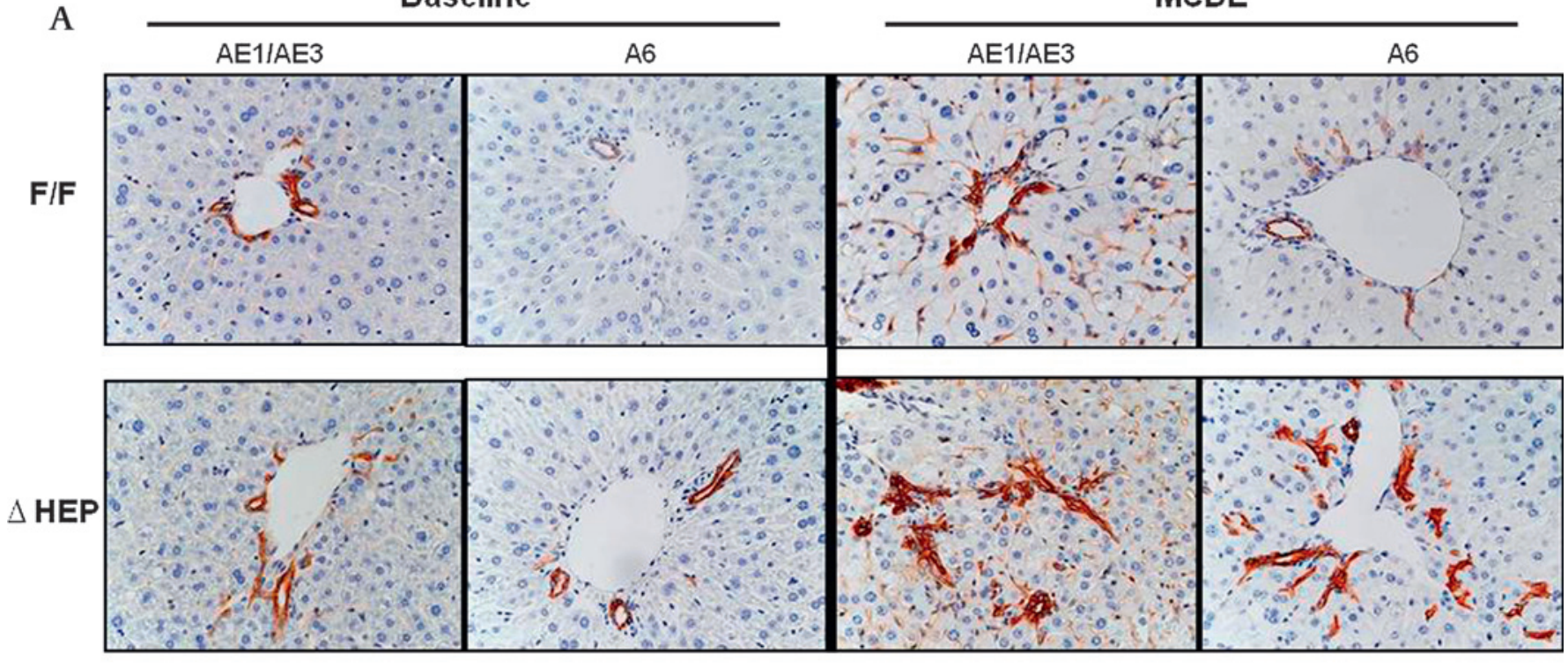

B

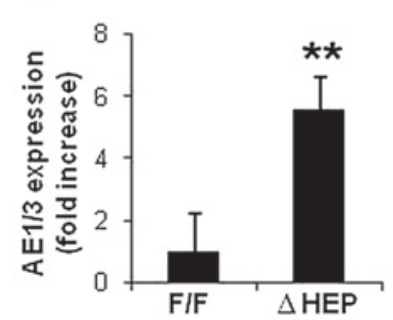

C

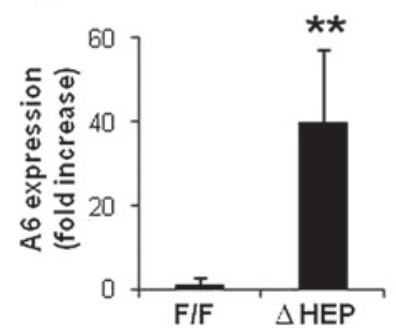

D

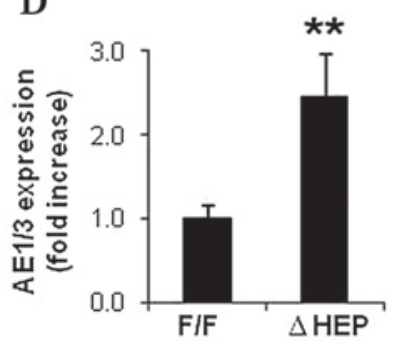

MCDE

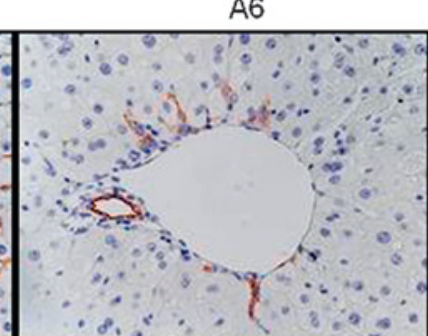

$\mathrm{E}$

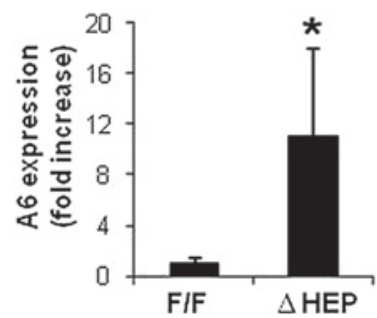

Figure 2 Increased hepatic progenitor populations in Ikk $\beta^{\Delta \text { Hep }}$ mice before and after hepatic damage. (A) Immunohistochemical staining for progenitor markers, AE1/AE3 and $A 6$, in liver sections from representative $1 \mathrm{kk} \beta^{\mathrm{F} / \mathrm{F}}$ and lkk $\beta^{\Delta \mathrm{Hep}}$ mice before (baseline) and after methionine cholinedeficient ethionine-supplemented (MCDE) diets for 1 week $(\times 40)$. Quantitative AE1/AE3 (B, D) or A6 $(C, E)$ immunohistochemistry data from Ikk $\beta^{F / F}$ and Ikk $\beta^{\Delta \text { Hep }}$ mice before $(B, A E 1 / A E 3 ; C, A 6)$ and after injury (D, AE1/AE3; E, A6). AE1/AE3- or A6-positive cells were measured by morphometry in eight portal tractss (PTS)/section. Mean $\pm S D$ are graphed $\left({ }^{*} p<0.05,{ }^{* *} p<0.005\right.$ vs the $1 k k \beta^{\mathrm{F} / \mathrm{F}}$ group).

undergoing apoptosis, and albumin, a marker for hepatocytes, confirmed that many albumin-positive hepatocytes from $\operatorname{Ikk} \beta^{\Delta \text { Hep }}$ mice were annexin $\mathrm{V}$ positive, whereas albumin-positive hepatocytes from $\operatorname{Ikk} \beta^{\mathrm{F} / \mathrm{F}}$ mice were generally negative for annexin V (figure 1D). Fluorescence-activated cell sorting (FACS) analysis of primary hepatocytes which were double-stained for annexin V and CD26, another marker for mature hepatocytes, verified that more hepatocytes from Ikk $\beta^{\Delta \mathrm{Hep}}$ mice were positive for annexin $\mathrm{V}$ (figure 1E). Hence, hepatocyte-specific deletion of Ikk $\beta$ increased baseline hepatocyte apoptotic activity.

To determine if this led to expansion of hepatocyte progenitor populations, livers from Ikk $\beta^{\Delta \mathrm{Hep}}$ mice and Ikk $\beta^{\mathrm{F} / \mathrm{F}}$ controls were stained for AE1/AE3 and A6, two different markers of liver progenitors. Compared with livers of $\mathrm{Ikk} \beta^{\mathrm{F} / \mathrm{F}}$ mice, livers of Ikk $\beta^{\Delta \text { Hep }}$ mice contained more AE1/AE3-positive cells, and more A6-positive cells at baseline (figure $2 \mathrm{~A}-\mathrm{C}$ ). Hence, hepatocytespecific deletion of Ikk $\beta$ expanded hepatic progenitor populations in seemingly healthy $\mathrm{Ikk} \beta^{\Delta \mathrm{Hep}}$ mice.

\section{Decreased nuclear localisation of NF- $\kappa B$ p65 and Ki67 expression in Ikk $\beta^{\Delta \text { Hep }}$ hepatocytes after liver injury}

To investigate the effects of superimposed liver injury on $\operatorname{Ikk} \beta^{\mathrm{F} / \mathrm{F}}$ and Ikk $\beta^{\Delta \text { Hep }}$ mice, we fed mice with MCDE diets for 1 week. This is known to induce liver injury and compensatory proliferation of liver progenitors in normal rodents. ${ }^{13}$ Only $50 \%$ of Ikk $\beta^{\Delta \text { Hep }}$ mice survived during MCDE treatment. Survivors also demonstrated less hepatomegaly than $\operatorname{Ikk} \beta^{\mathrm{F} / \mathrm{F}}$ mice (liver weight (LW)/body weight (BW) ratio $5.09 \pm 0.41 \%$ vs $7.22 \pm 1.02 \%, p<0.05$ ).

Hepatic injury generally activates the Ikk complex. This allows cytosolic NF- $\kappa \mathrm{B}$ to translocate into the nuclear compartment, eventually exerting viability functions in hepatocytes. Because Ikk $\beta^{\Delta \text { Hep }}$ mice have been reported to exhibit impaired NF- $\kappa \mathrm{B}$ activation, we compared the nuclear localisation of NF- $\kappa B$ in $\operatorname{Ikk} \beta^{\mathrm{F} / \mathrm{F}}$ and Ikk $\beta^{\Delta \mathrm{Hep}}$ mice after MCDE treatment. As assessed by IHC, Ikk $\beta^{\mathrm{F} / \mathrm{F}}$ and $\operatorname{Ikk} \beta^{\Delta H e p}$ mice exhibited dramatic differences in NF- $\kappa B$ localisation in response to liver injury. Strong nuclear localisation of NF- $\kappa B$ p 65 was observed in MCDE-fed Ikk $\beta^{\mathrm{F} / \mathrm{F}}$ mice, whereas relatively few hepatocyte nuclei contained NF- $\kappa B$ p65 in MCDE-fed Ikk $\beta^{\Delta \text { Hep }}$ mice (figure

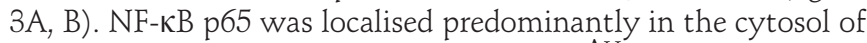
both hepatocytic and ductular cells in Ikk $\beta^{\Delta \text { Hep }}$ mice (figure $3 \mathrm{~A}$, $B$ and Supplementary figure 2). Therefore, after liver injury, Ikk $\beta^{\Delta \text { Hep }}$ mice had more NF- $\kappa B$ p65 in hepatocyte cytosol and less NF- $\mathrm{BB}$ p65 in hepatocyte nuclei than Ikk $\beta^{\mathrm{F} / \mathrm{F}}$ mice.

To determine if these changes in NF- $\mathrm{KB}$ localisation were associated with differences in hepatocyte proliferative responses, liver sections from MCDE-fed Ikk $\beta^{\mathrm{F} / \mathrm{F}}$ and Ikk $\beta^{\Delta \mathrm{Hep}}$ mice were stained for Ki67, a marker of $\mathrm{S}$ phase. The injured livers of $\operatorname{Ikk} \beta^{\mathrm{F} / \mathrm{F}}$ mice contained 20-fold more Ki67-positive hepatocytic cells than those of Ikk $\beta^{\Delta \text { Hep }}$ mice (figure $3 C, E$ ). Interestingly, although Ikk $\beta^{\Delta \text { Hep }}$ mice had reduced hepatocyte replication, these mice demonstrated greater proliferation of ductular cells than $\mathrm{Ikk} \beta^{\mathrm{F} / \mathrm{F}}$ mice, 
Figure 3 Reduced nuclear localisation

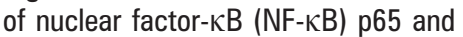
decreased hepatoctye Ki67 expression in $\mathrm{lkk} \beta^{\Delta \mathrm{Hep}}$ mice after hepatic injury. (A) Immunohistochemical staining for NF$\kappa B$ p65 in liver from representative $\mathrm{lkk} \beta^{\mathrm{F} / \mathrm{F}}$ and $\mathrm{lkk} \beta^{\Delta \mathrm{Hep}}$ mice before (baseline) and after methionine cholinedeficient ethionine-supplemented (MCDE) diets for 1 week $(\times 40)$. (B) Quantitative NF-кB p65 immunohistochemistry data from MCDE-fed mice ( $n=4$ mice/group). The numbers of hepatocytic cells (HEP) or ductular cells with nuclear or cytosolic NF- $\kappa B$ p65 were counted in eight portal tracts (PTs)/section. Results are expressed as numbers of NF- $\kappa B$ p $65(+)$ cells per PT and graphed as mean $\pm S D$ results ( ${ }^{*} p<0.05$, ${ }^{* *} p<0.005$ vs the Ikk $\beta^{\mathrm{F} / \mathrm{F}}$ MCDE-fed group). (C, D) Immunohistochemical staining with Ki67 (cell proliferation marker) in liver sections from representative $\operatorname{lkk} \beta^{\mathrm{F} / \mathrm{F}}$ (D) and $\operatorname{lkk} \beta^{\Delta \mathrm{Hep}}(\mathrm{E})$ mice after MCDE dietinduced liver injury. (E) Quantitative Ki67 immunohistochemistry data from all mice ( $n=4$ mice/group). The numbers of Ki67(+) HEPs and ductular cells were counted in eight PTs/section. Ki67(+) HEPs were quantified by counting the total number of Ki67 $(+)$ HEPs/field and dividing by the total number of HEPs/ field. Ki67(+) ductular cells were quantified by dividing the total number of positive cells by the total number of PTs. Mean $\pm S D$ results are graphed $\left({ }^{*} \mathrm{p}<0.05,{ }^{* *} \mathrm{p}<0.005\right.$ vs the $\mathrm{Ikk} \beta^{\mathrm{F} / \mathrm{F}}$ chow-fed control group).
A

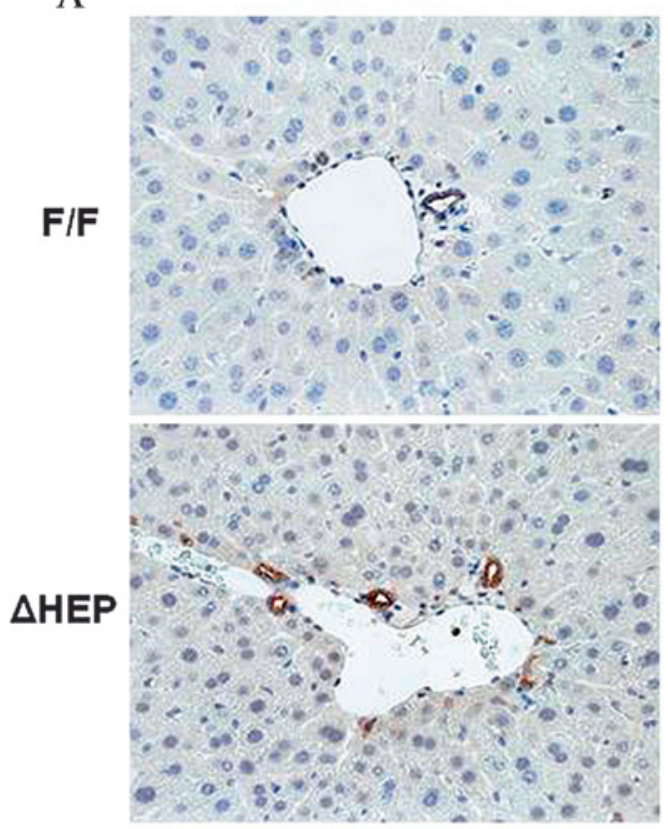

B
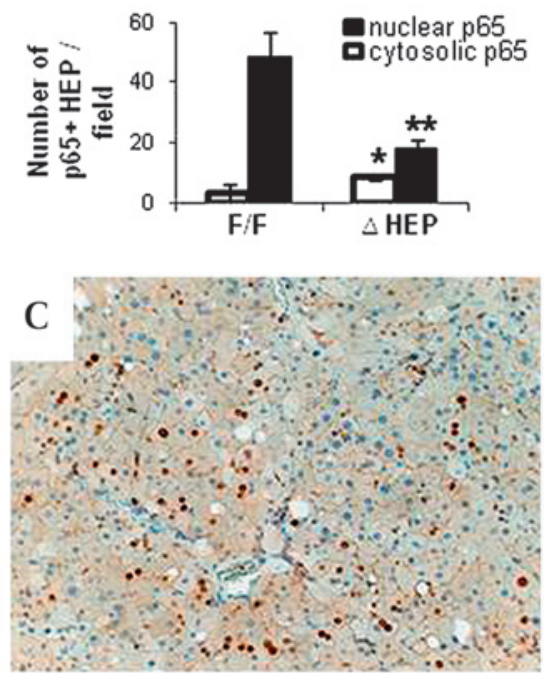

E

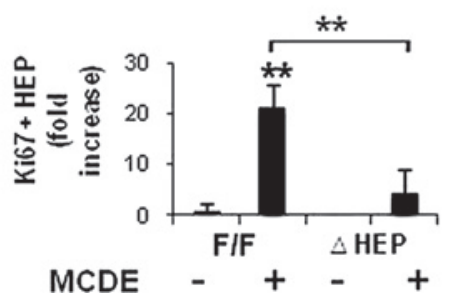

MCDE
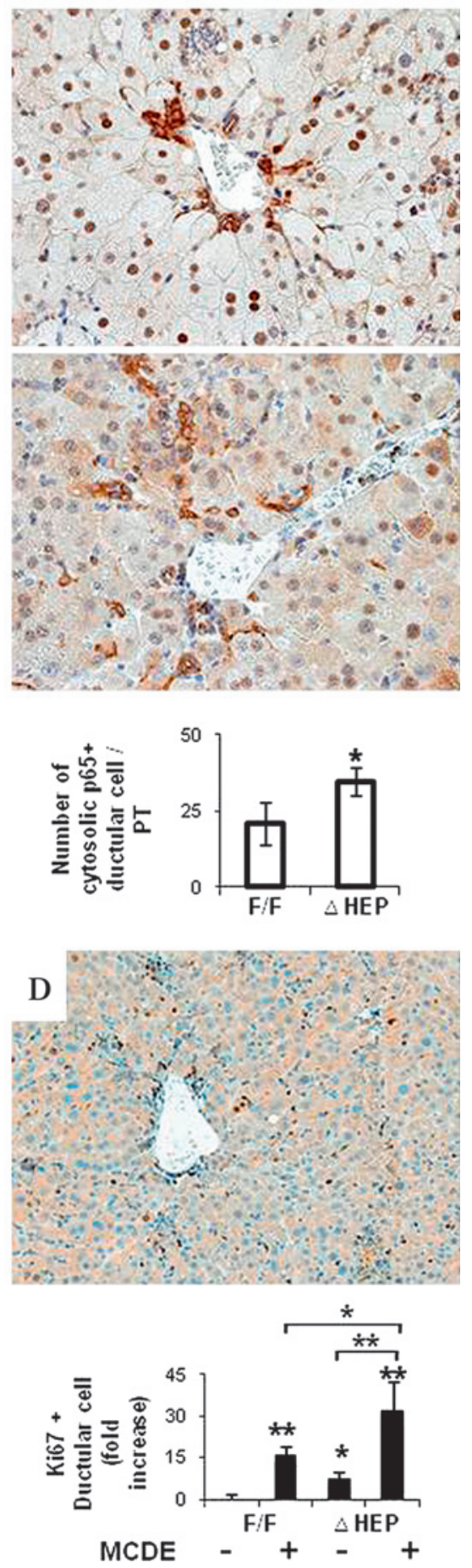

both at baseline and after liver injury (figure 3D, E). Because the ductular cell population is enriched with liver progenitors, ${ }^{14}$ these findings suggested that hepatocyte-specific deletion of $\operatorname{Ikk} \beta$ promoted proliferation of liver progenitor populations.

\section{Increased progenitors in Ikk $\beta^{\Delta \text { Hep }}$ mice during liver damage}

To investigate this possibility further, livers from MCDE diet-fed $\operatorname{Ikk} \beta^{\mathrm{F} / \mathrm{F}}$ and Ikk $\beta^{\Delta \mathrm{Hep}}$ mice were stained for the progenitor markers, $\mathrm{AE} 1 / 3$ and $\mathrm{A} 6$. Liver injury induced greater accumulation of AE1/ AE3-positive cells in Ikk $\beta^{\Delta \mathrm{Hep}}$ mice than in Ikk $\beta^{\mathrm{F} / \mathrm{F}}$ mice (figure $2 \mathrm{~A}$, D). Similarly, numbers of A6-positive progenitors were also greater in Ikk $\beta^{\Delta \mathrm{Hep}}$ mice than in I $k \mathrm{k} \beta^{\mathrm{F} / \mathrm{F}}$ mice (figure $2 \mathrm{~A}, \mathrm{E}$ ). Therefore, hepatocyte-specific deletion of Ikk $\beta$ promoted compensatory expansion of progenitor populations after liver injury.

\section{Increased Hh signalling in Ikk $\beta^{\Delta H e p}$ mice promotes progenitor viability}

Evidence that mature hepatocytes from Ikk $\beta^{\Delta \mathrm{Hep}}$ mice were prone to apoptosis, but that progenitors accumulated in Ikk $\beta^{\Delta \text { Hep }}$ livers, suggested that hepatic progenitors might have survival mechanisms that were distinct from those that operate in mature hepatocytes. Since activation of theHh pathway is known to 
Figure 4 Cell type-specific differences in survival factor signalling in progenitors and mature hepatocytes from Ikk $\beta^{\Delta H e p}$ and Ikk $\beta^{\Delta H e p}$ mice. (A) Primary hepatocytes and liver progenitors were harvested from $\mathrm{Ikk} \beta^{\mathrm{F} / \mathrm{F}}$ and $\mathrm{lkk} \beta^{\Delta \text { Hep }}$ mice ( $n=15$ mice/group). Due to the relatively low numbers of progenitors in adult livers, progenitor cells were pooled from 2-3 mice/group for RNA and protein extraction. Quantitative reverse transcription-PCR (qRT-PCR) analysis of RNA expression of the mutant Ikk $\beta$ allele, albumin, Cre recombinase (cre) and glyceraldehyde phosphate dehydrogenase (gapdh) in representative mice. Western blot analysis of Gli2 (133 kDa) and $\beta$ actin expression in the same mice.

(B) Primary progenitors from both groups were then cultured with cyclopamine $(3 \mu \mathrm{M})$ or tomatidine $(3 \mu \mathrm{M})$ for $24 \mathrm{~h}$. Control wells were treated with an equal volume of vehicle (dimethylsulfoxide (DMSO)) for the same treatment period. At the end of the treatment period, growth (cell number) was assessed using the CCK-8 assay. Each experiment was replicated three times. Mean $\pm S D$ results are graphed $\left({ }^{*} \mathrm{p}<0.05,{ }^{*} \mathrm{p}<0.005\right.$ vs respective the $0 \mathrm{~h}$ control group). (C) QRT-PCR analysis of liver RNA from chow-fed $\mathrm{lkk} \beta^{\mathrm{F} / \mathrm{F}}$ and $\mathrm{lkk} \beta^{\Delta \mathrm{Hep}}$ mice (open bars), and methionine choline-deficient ethioninesupplemented (MCDE) diet-fed Ikk $\beta^{\mathrm{F} / \mathrm{F}}$ and Ikk $\beta^{\Delta \text { Hep }}$ mice (black bars) for Indian hedgehog (Ihh), Patched (Ptc), Gli2 and frizzled-related peptide (Frp)1 ( $n=4$ mice/group/treatment).

Mean \pm SD results are graphed $\left({ }^{*} \mathrm{p}<0.05\right.$, ${ }^{* *} \mathrm{p}<0.005$ vs the $\mathrm{lkk} \beta^{\mathrm{F} / \mathrm{F}}$ chow-fed control group).
A

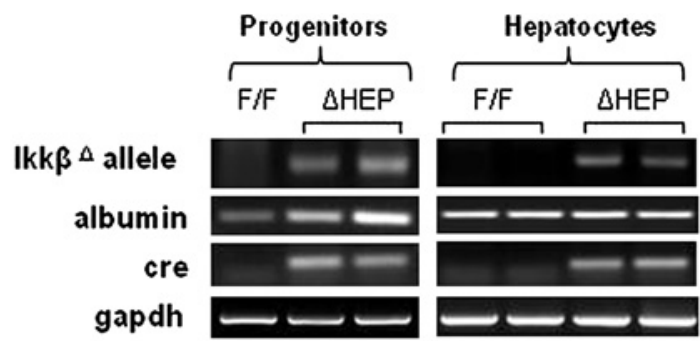

protein
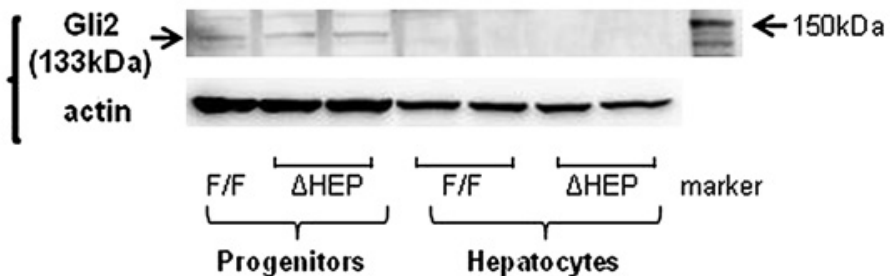

B

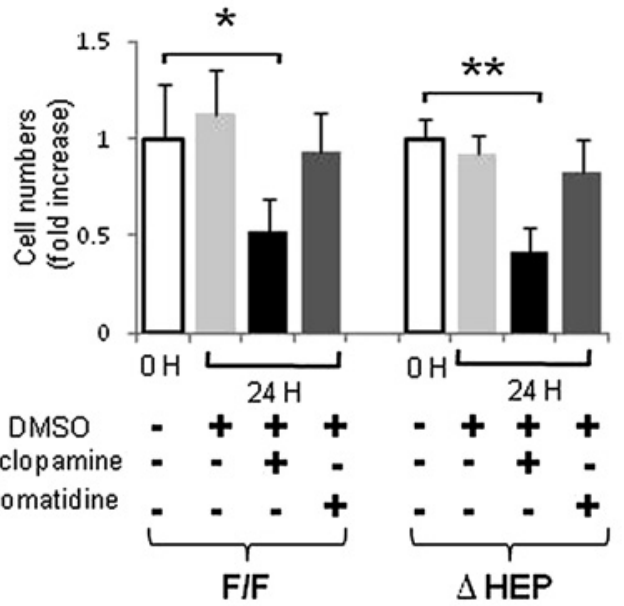

\section{C 口chow MCDE}
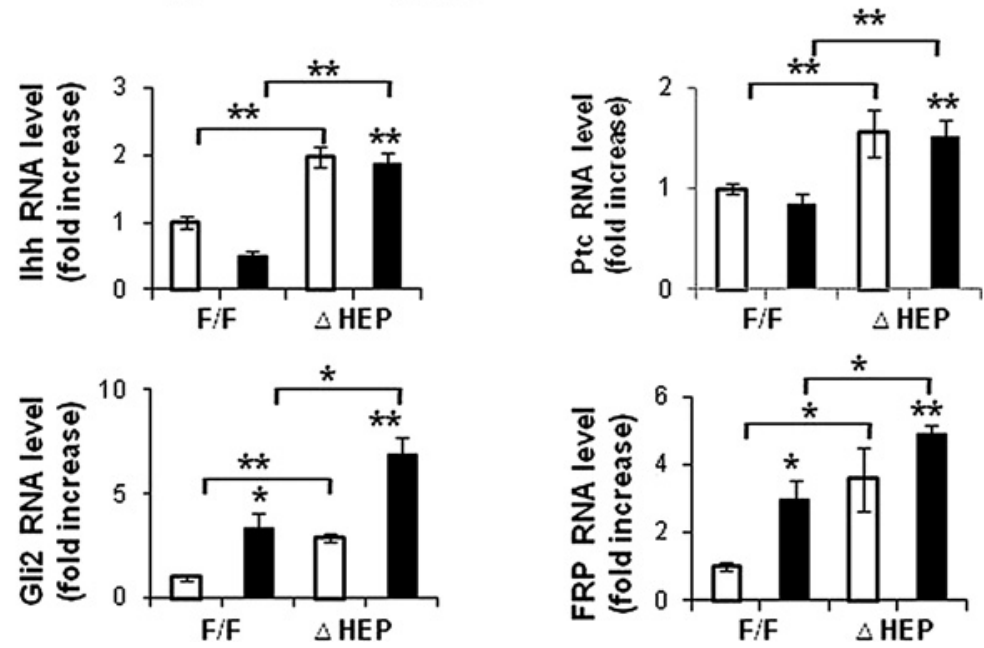

regulate the viability of many types of progenitors, including fetal liver progenitors and ductular-type progenitors in adult livers, ${ }^{8}$ we next evaluated Hh pathway activity in Ikk $\beta^{\Delta \mathrm{Hep}}$ mice.

First we clarified which types of liver cells were capable of $\mathrm{Hh}$ signalling by isolating progenitor populations and mature hepatocytes from healthy Ikk $\beta^{\Delta \text { Hep }}$ mice and Ikk $\beta^{\mathrm{F} / \mathrm{F}}$ controls. In both cell types, we compared expression of the mutant $\operatorname{Ikk} \beta$ allele, albumin and Cre recombinase, and correlated those results with expression of Gli2 protein, a marker of $\mathrm{Hh}$ signalling. Results in progenitors from Ikk $\beta^{\mathrm{F} / \mathrm{F}}$ mice were compared with findings in progenitors from Ikk $\beta^{\Delta \mathrm{Hep}}$ mice. Although progenitor populations from $\operatorname{Ikk} \beta^{\mathrm{F} / \mathrm{F}}$ and $\mathrm{Ikk} \beta^{\Delta \mathrm{Hep}}$ mice all expressed albumin mRNA, only the Ikk $\beta^{\Delta \text { Hep }}$ progenitors expressed Cre recombinase and the mutant Ikk $\beta$ allele. Similarly, expression of Cre and the mutant Ikk $\beta$ allele was noted only in mature hepatocytes from $\operatorname{Ikk} \beta^{\Delta \mathrm{Hep}}$ mice (figure $4 \mathrm{~A}$ ).

Despite these engineered differences in $\operatorname{Ikk} \beta$ expression, immunohistochemistry demonstrated that NF- $\mathrm{KB}$ p65 remained mostly cytosolic in ductular-type progenitors during liver injury in both Ikk $\beta^{\mathrm{F} / \mathrm{F}}$ and Ikk $\beta^{\Delta \mathrm{Hep}}$ mice (Supplementary figure 2). This finding suggested that liver progenitors may not require nuclear localisation of NF-kB p65 to survive liver injury. In contrast, 
progenitor populations from both $\operatorname{Ikk} \beta^{\mathrm{F} / \mathrm{F}}$ and $\operatorname{Ikk} \beta^{\Delta \mathrm{Hep}}$ mice expressed Gli2 proteins, whereas mature hepatocytes from neither strain expressed Gli2 (figure 4A). Thus, the hepatic progenitor populations were capable of activating Hh signalling and retained this capability even when their NF- $\kappa \mathrm{B}$ pathway was disrupted.

To investigate the role of $\mathrm{Hh}$ signalling in maintaining progenitor viability during liver injury more directly, we isolated progenitor populations from MCDE-fed Ikk $\beta^{\mathrm{F} / \mathrm{F}}$ and Ikk $\beta^{\Delta \mathrm{Hep}}$ mice, placed them in culture and treated the cultures with vehicle, cyclopamine, a specific pharmacological inhibitor of the Hh pathway, ${ }^{15}$ or tomatidine, an inactive cyclopamine analogue. The effects on cell numbers were quantified. Neither vehicle nor tomatidine altered the number of $\mathrm{Ikkb}{ }^{\mathrm{F} / \mathrm{F}}$ or $\mathrm{Ikk} \beta^{\Delta \mathrm{Hep}}$ progenitors. In contrast, cyclopamine significantly reduced progenitor numbers in both groups, decreasing cell counts by $>50 \%$ within $24 \mathrm{~h}$ (figure 4B). Hence, Hh signalling permitted the survival of liver progenitor populations during chronic liver injury, including the Ikk $\beta^{\Delta \text { Hep }}$ progenitors that had a defective NF- $\kappa B$ pathway.

\section{Increased expression of Hh ligands and target genes in livers of lkk $\beta^{\Delta \text { Hep }}$ mice}

Because progenitor populations were increased in the livers of Ikk $\beta^{\Delta \text { Hep }}$ mice, both at baseline and during superimposed injury, we next asked if the Hh pathway was generally activated in mice with disruption of Ikk-NF- $\mathrm{KB}$ signalling in hepatocytes. Compared with Ikk $\beta^{\mathrm{F} / \mathrm{F}}$ mice, Ikk $\beta^{\Delta \mathrm{Hep}}$ mice had greater mRNA expression of the $\mathrm{Hh}$ ligand, Indian $\mathrm{Hh}$ (Ihh), and several Hh target genes, including the Hh receptor, Patched (Ptc), Gli2, a Hh-regulated transcription factor, and frizzledrelated peptide (Frp)-1, a Hh target gene and soluble inhibitor of canonical Wnt signalling, both before and after liver injury (figure 4C).
Disrupting the Ikk-NF- $\mathrm{B}$ pathway in hepatocytes triggers their production of Hh ligands

Since differences in $\mathrm{Hh}$ pathway activation between $\operatorname{Ikk} \beta^{\Delta \mathrm{Hep}}$ and $\mathrm{Ikk} \beta^{\mathrm{F} / \mathrm{F}}$ mice accompany targeted deletion of $\operatorname{Ikk} \beta$ in mature hepatocytes, we isolated primary hepatocytes from Ikk $\beta^{\mathrm{F} / \mathrm{F}}$ and wild-type mice and treated the cells with adenoviral vectors carrying either Cre recombinase (AdCre) or green fluorescent protein (AdGFP) to determine if acutely deleting $\operatorname{lkk} \beta$ function influenced hepatocyte production of $\mathrm{Hh}$ ligands (figure 5). Incubation with AdGFP efficiently transduced virtually all of the hepatocytes and did not reduce cell viability or affect $\mathrm{Hh}$ ligand expression. Similarly, treating wild-type hepatocytes with AdCre had no effect on either of these parameters. In contrast, AdCre treatment significantly reduced viability and increased mRNA expression of Ihh ligand in hepatocytes from $\operatorname{Ikk} \beta^{\mathrm{F} / \mathrm{F}}$ mice (figure 5A,B). Western blot analysis of protein lysates from $\operatorname{Ikk} \beta^{\mathrm{F} / \mathrm{F}}$ hepatocytes that were treated with AdGFP or AdCre demonstrated that acute AdCre-mediated disruption of $\mathrm{Ikk} \beta$ led to caspase 3 activation and increased cellular production of both Shh and Ihh proteins (figure 5C,D). However, AdCre-treated hepatocytes did not exhibit increased expression of Hh target genes, such as Ptc or Gli2 (data not shown). Therefore, interrupting $\operatorname{Ikk} \beta$ function in isolated hepatocytes reduced their viability and induced them to produce Hh ligands that function as viability factors for liver progenitors.

\section{Increased production of Hh ligands causes hepatic accumulation} of Hh-responsive cells

Subsequent experiments used IHC for the Hh-regulated transcription factor Gli2, to identify which types of liver cells were $\mathrm{Hh}$ responsive in intact animals. Although few Gli2-positive cells were evident in the uninjured livers of either $\operatorname{Ikk} \beta^{\mathrm{F} / \mathrm{F}}$ or Ikk $\beta^{\Delta \text { Hep }}$ mice, quantitative analysis demonstrated that
Figure 5 Deleting Ikk $\beta$ (inhibitor kappa $B$ kinase subunit $\beta$ ) in hepatocytes promotes production of Hedgehog (Hh) ligands. (A) Primary hepatocytes were isolated from wildtype (WT) and $\mathrm{lkk} \beta^{\mathrm{F} / \mathrm{F}}$ mice $(\mathrm{n}=5 /$ group) and cultured in the presence of adenoviral vectors carrying green fluorescent protein (AdGFP) or Cre recombinanse (AdCre). Cultures were analysed at 24 and $48 \mathrm{~h}$. In each experiment, quintuplicate wells were assayed. Each experiment was replicated three times. (A) Cell numbers were measured by CCK-8 assay and (B) Indian hedgehog ligand (Ihh) expression was evaluated by quantitative reverse transcription-PCR analysis. Mean \pm SD results are graphed $\left({ }^{*} \mathrm{p}<0.05\right.$, ${ }^{*} \mathrm{P}<0.005$ vs AdGFP-treated cells in the Ikk $\beta^{\mathrm{F} / \mathrm{F}}$ group). (C) Representative western blot analysis of caspase 3, Sonic hedgehog (Shh) and Ihh ligands in primary hepatocytes isolated from $\mathrm{Ikk}^{\mathrm{F} / \mathrm{F}}$ mice and treated with either AdGFP or AdCre for 24 or 48 h. (D) Cumulative densitometric analyses of Shh and Ihh western blots results are displayed as the mean $\pm S D$ ( ${ }^{* *} p<0.005$ vs AdGFP-treated cells in the $1 \mathrm{kk} \beta^{\mathrm{F} / \mathrm{F}}$ group).
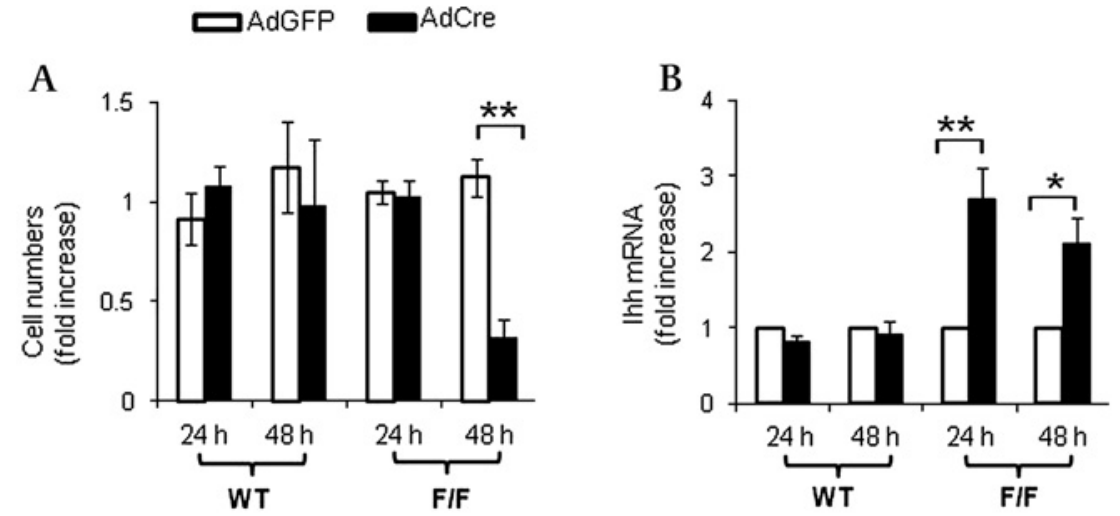

C

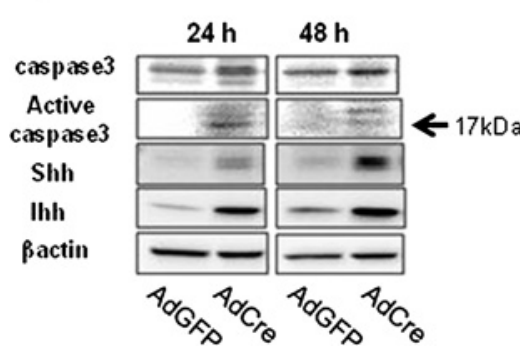

D

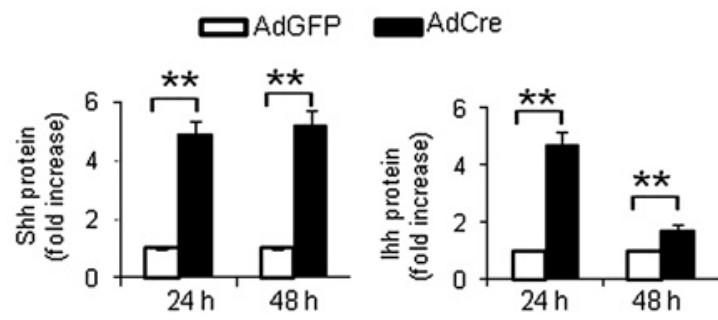


Figure 6 Increased accumulation of Hedgehog (Hh)-responsive cells in Ikk $\beta^{\Delta \text { Hep }}$ mice after liver injury. (A) Immunohistochemical staining for Gli2 in representative $\mathrm{Ikk} \beta^{\mathrm{F} / \mathrm{F}}$ and Ikk $\beta^{\Delta \mathrm{Hep}}$ mice before (baseline) and after methionine choline-deficient ethioninesupplemented (MCDE) diets for 1 week $(\times 40)$. (B, C) Quantitative Gli2 immunohistochemistry data from all mice ( $n=4$ mice/group). Gli2(+) hepatocytic cells (HEPs) or ductular cells were counted in eight $(\times 40$ magnification) fields that contained portal tractss (PTs). (B) Gli2(+) hepatocytic cells were expressed as a percentage of Gli2 $(+)$ hepatocyte nuclei/total HEPs. (C) Gli2(+) ductular cells were quantified by dividing the total number of positive cells by the total number of PTs. Mean \pm SD results are graphed $\left({ }^{*} p<0.05,{ }^{* *} p<0.005\right.$ vs the Ikk $\beta^{\mathrm{F} / \mathrm{F}}$ chow-fed control group). (D) Double immunohistochemical staining with Gli2 (brown) and pancytokeratin (blue) in Ikk $\beta^{\Delta \text { Hep }}$ mice after MCDE treatment (original magnification $\times 63$ ).
A
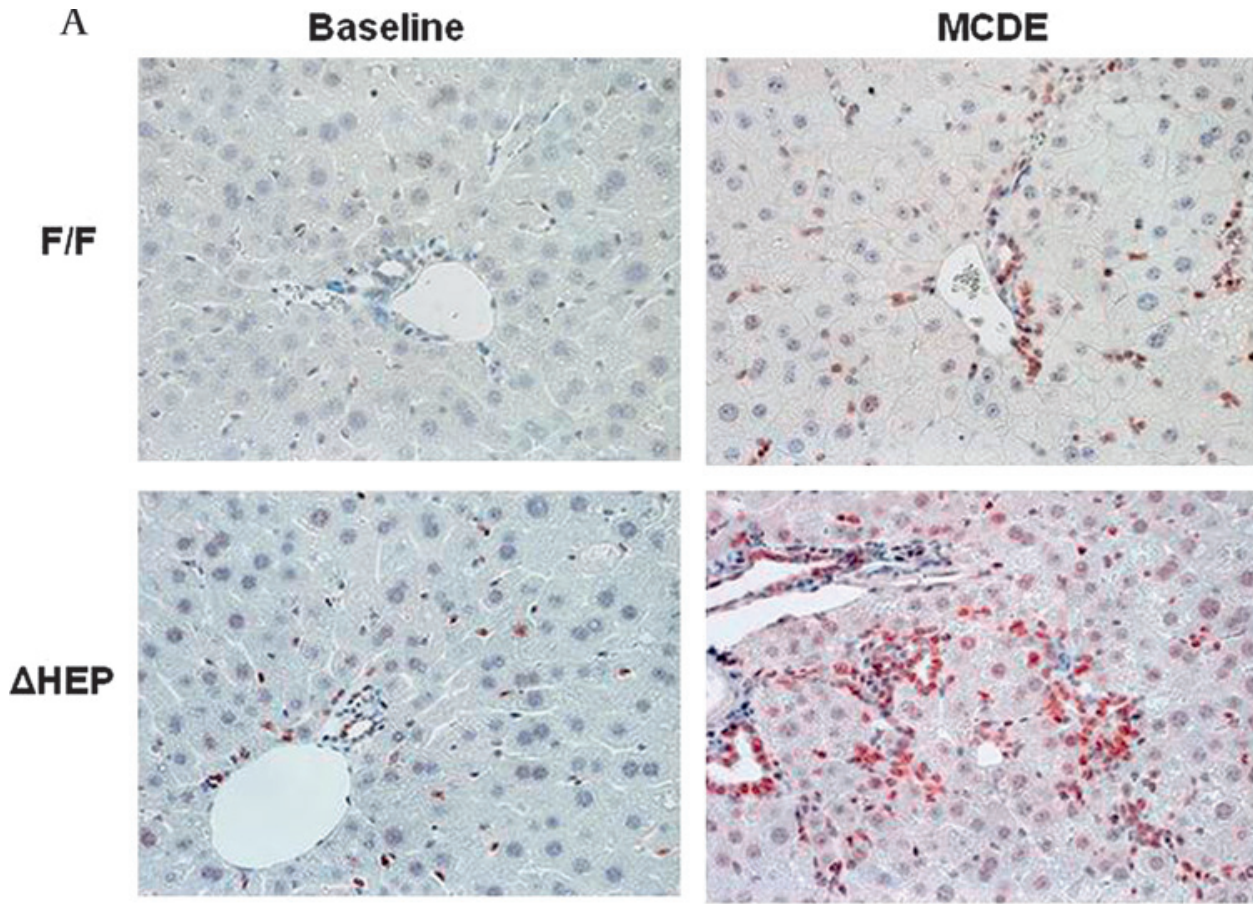

B
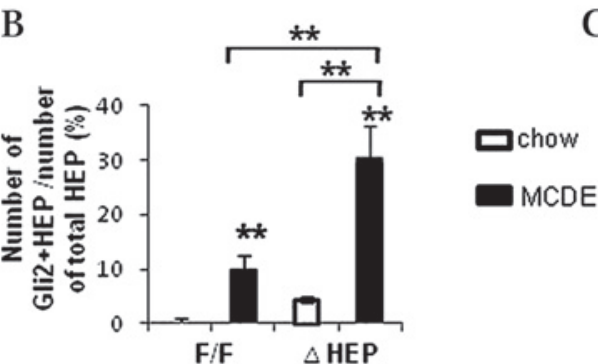

C
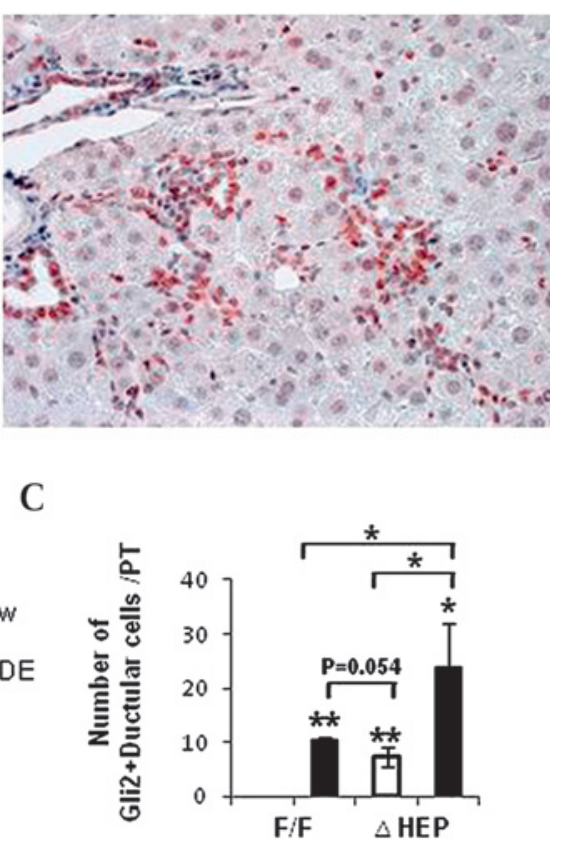

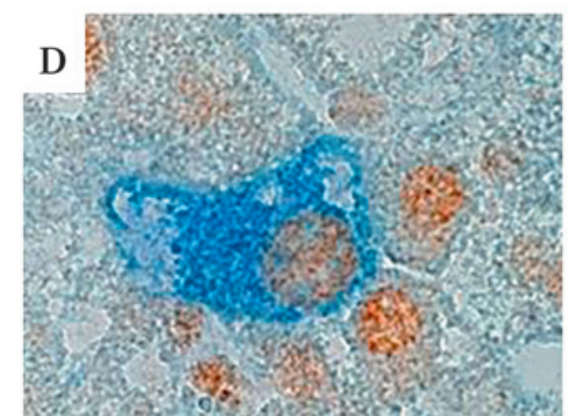

Ikk $\beta^{\Delta \text { Hep }}$ mice had more Gli-positive hepatocytic cells and Glipositive ductular cells than $\operatorname{Ikk} \beta^{\mathrm{F} / \mathrm{F}}$ mice at baseline. The numbers of Gli2-positive cells increased in both groups after MCDE diet treatment, but the greatest numbers of these $\mathrm{Hh}$ responsive cells accumulated in Ikk $\beta^{\Delta \text { Hep }}$ livers (figure $6 \mathrm{~A}-\mathrm{C}$ ). After only 1 week of diet-induced liver injury, the net numbers of Hh-responsive cells were about threefold greater in Ikk $\beta^{\Delta \text { Hep }}$ mice than in $\operatorname{Ikk} \beta^{\mathrm{F} / \mathrm{F}}$ mice.

Evidence that neither mature hepatocytes from Ikk $\beta^{\mathrm{F} / \mathrm{F}}$ mice nor hepatocytes from Ikk $\beta^{\Delta \text { Hep }}$ mice expressed Gli2 at baseline, and that targeted disruption of $\operatorname{lkk} \beta$ function in cultured hepatocytes failed to activate expression of Hh-regulated genes suggested that the Gli2-positive hepatocytic cells in injured livers might have been derived from Hh-responsive progenitors that survived liver injury and then partially differentiated to replace dead hepatocytes. This concept was evaluated by double immunostaining liver sections for Gli2 and pancytokeratin, a marker of immature hepatocytes. ${ }^{16}$ Co-localisation of Gli2 and pancytokeratin was demonstrated in hepatocytic cells, particularly periportally (figure 6D), supporting the possibility that Gli2-expressing hepatocytic cells in Ikk $\beta^{\Delta \mathrm{Hep}}$ mice were immediate progeny of Gli2-positive progenitors that survived liver injury.

\section{Enhanced fibrogenesis and liver fibrosis in Ikk $\beta^{\Delta \text { Hep }}$ mice, and increased hepatocyte expression of Shh in patients with liver fibrosis}

Hepatocytes in healthy livers lack a basement membrane and, hence, are immediately adjacent to HSCs that reside in the space of Disse. Cells that produce Hh ligands release these factors in 
Figure 7 Enhanced fibrogenesis and liver fibrosis in Ikk $\beta^{\Delta \text { Hep }}$ mice. (A) $\alpha$ Smooth muscle actin ( $\alpha \mathrm{sma}$ ) expression was assessed in whole liver proteins from Ikk $\beta^{\mathrm{F} / \mathrm{F}}$ and $\mathrm{lkk} \beta^{\Delta \mathrm{Hep}}$ mice ( $n=3 /$ group/treatment) using western blot analysis. (B) Sirius red staining in liver sections from representative mice $(\times 20$ or $\times 40)$. The graph demonstrates the mean $\pm S D$ morphometric data from all mice ( $n=4 /$ group/greatment). (C) Hepatic hydroxyproline content in all mice ( $n=4$ mice/group). All results are displayed as mean \pm SD $\left({ }^{*} p<0.05\right.$, ${ }^{* *} \mathrm{p}<0.005$ vs the Ikk $\beta^{\mathrm{F} / \mathrm{F}}$ chow-fed control group). MCDE, methionine choline-deficient ethioninesupplemented.
A

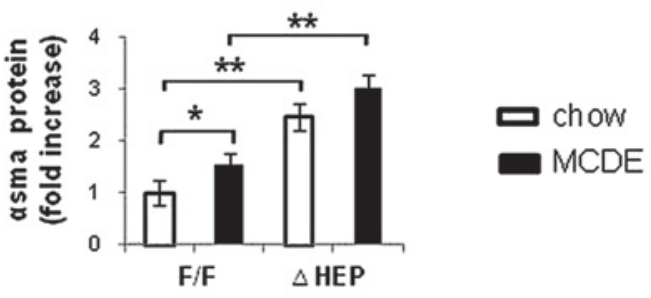

B
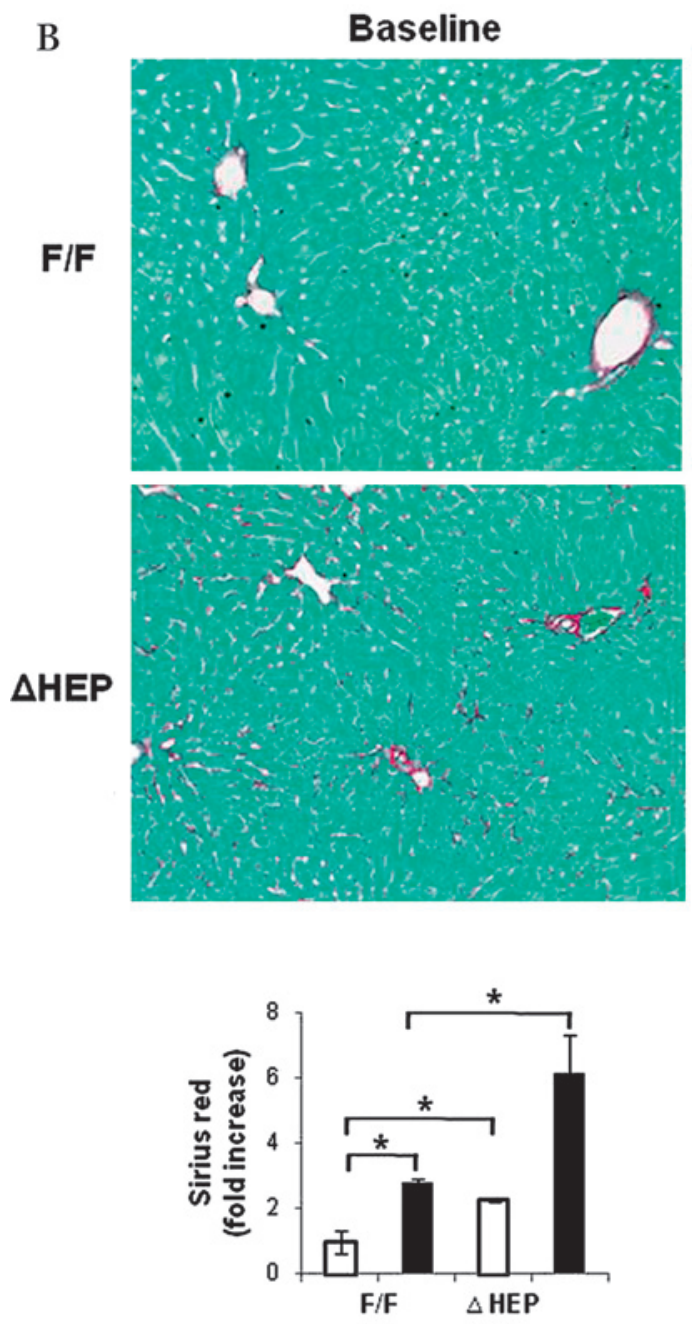
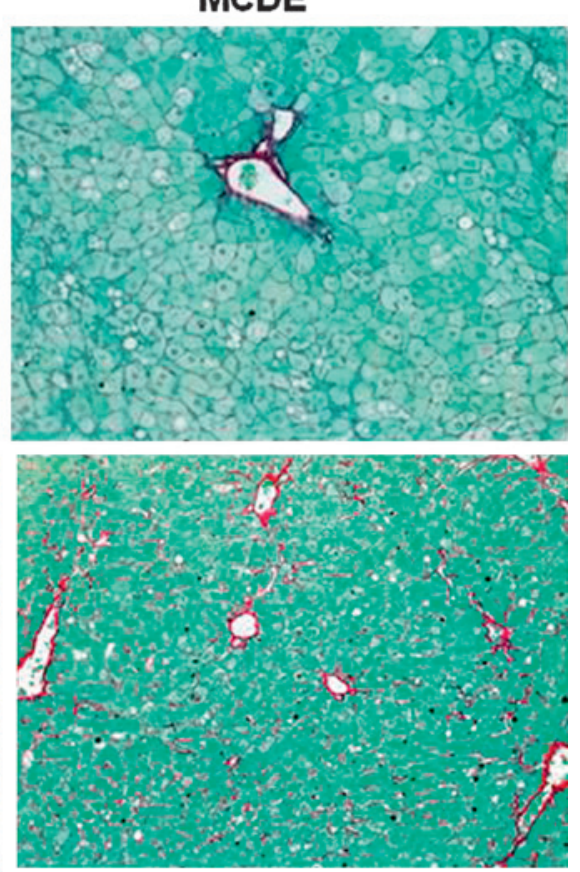

C
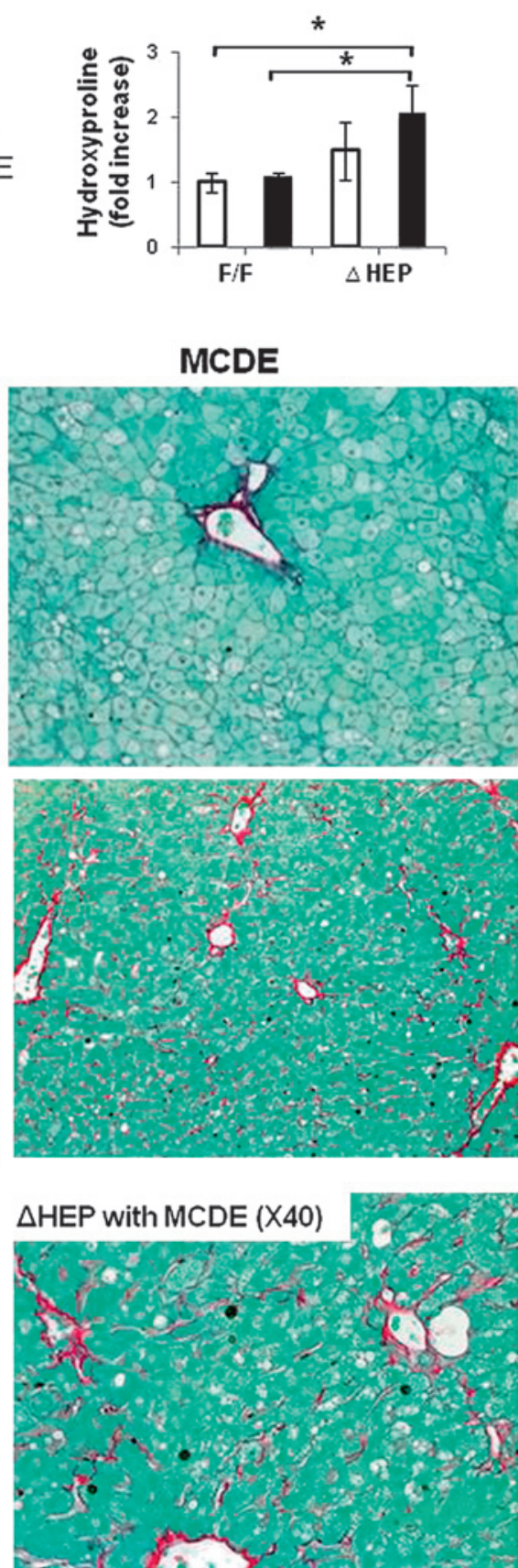

membranous particles, and this process increases during apoptosis. ${ }^{17}$ Thus, HSCs are proximal targets of Hh ligands that are released from hepatocytes in injured livers. This may promote fibrogenesis because $\mathrm{Hh}$ ligands activate quiescent HSCs to become myofibroblastic $(\mathrm{MF})^{18}$ and promote the viability and proliferation of MF-HSCs. ${ }^{19}$ To assess this issue, we performed western blot analysis to compare expression of $\alpha$-smooth muscle actin ( $\alpha$-SMA), a marker of MF-HSCs, in $\operatorname{Ikk} \beta^{\mathrm{F} / \mathrm{F}}$ and Ikk $\beta^{\Delta \mathrm{Hep}}$ mice. Levels of $\alpha$-SMA protein were significantly greater in the Ikk $\beta^{\Delta \text { Hep }}$ group, both before and after MCDE diet treatment (figure 7A). Sirius red staining demonstrated that $\operatorname{Ikk} \beta^{\Delta \text { Hep }}$ mice also had more pericellular and sinusoidal deposition of collagen fibrils than $\operatorname{Ikk} \beta^{\mathrm{F} / \mathrm{F}}$ mice at both time points (figure $7 \mathrm{~B}$ ). Biochemical determination of hepatic hydroxyproline content, a quantitative measure of liver fibrosis, confirmed that Ikk $\beta^{\Delta \text { Hep }}$ mice had significantly more liver fibrosis than $\operatorname{Ikk} \beta^{\mathrm{F} / \mathrm{F}}$ mice (figure 7C). Therefore, activation of the Hh pathway promoted accumulation of MF cells and increased fibrogenesis in mice with chronically increased hepatocyte apoptosis.

To determine if a similar process might occur in humans, we performed immunostaining for Shh and $\alpha$-SMA on liver biopsy samples from 12 patients with early (stage F2) or advanced (stage F4) fibrosis due to chronic NASH. In parallel, similar staining was done on healthy control liver tissue. NASH livers were selected for scrutiny because levels of hepatic apoptotic activity correlate with the severity of liver fibrosis in this disease. ${ }^{20}$

No Shh-positive hepatocytes were identified in healthy control livers (data not shown). In NASH livers, hepatocytes that stained for Shh were variably detected, with greater numbers of more strongly stained hepatocytes occurring in livers with more fibrosis (figure $8 \mathrm{~A}-\mathrm{C}$, Supplementary figure $3 \mathrm{~A}, \mathrm{~B}$ ). Fibrotic NASH livers typically demonstrated foci of hepatocytes 
Figure 8 Increased expression of Hedgehog $(\mathrm{Hh})$ ligand by hepatocytes in patients with non-alcoholic steatohepatitis (NASH) with fibrosis Immunohistochemistry was used to assess Sonic hedgehog (Shh) and $\alpha$-smoothe muscle actin ( $\alpha$-SMA) expression in healthy control livers $(n=3)$ and in livers from patients with NASH with early (F2) fibrosis $(n=6)$ or advanced (F4) fibrosis $(n=6)$.

Representative photomicrographs are shown. (A) Negative control for Shh immunostaining in which the primary anti-Shh antibody was eliminated and the section was exposed to secondary antibody only. (B) NASH liver with early fibrosis shows hepatocytes that express no Shh (thin arrow), low levels of Shh (arrowhead) or higher levels of Shh $\left({ }^{*}\right)$. (C) NASH liver with advanced fibrosis shows many hepatocytes that are strongly stained for Shh. (D) Single immunostaining for $\alpha$-SMA (brown) in NASH liver with early fibrosis.

(E) Double staining for $\alpha$-SMA (blue) and Shh (brown) in NASH liver with early fibrosis. (F) Double staining for $\alpha$ SMA and Shh in healthy control liver $(A-C: \times 40, D-F: \times 100)$.
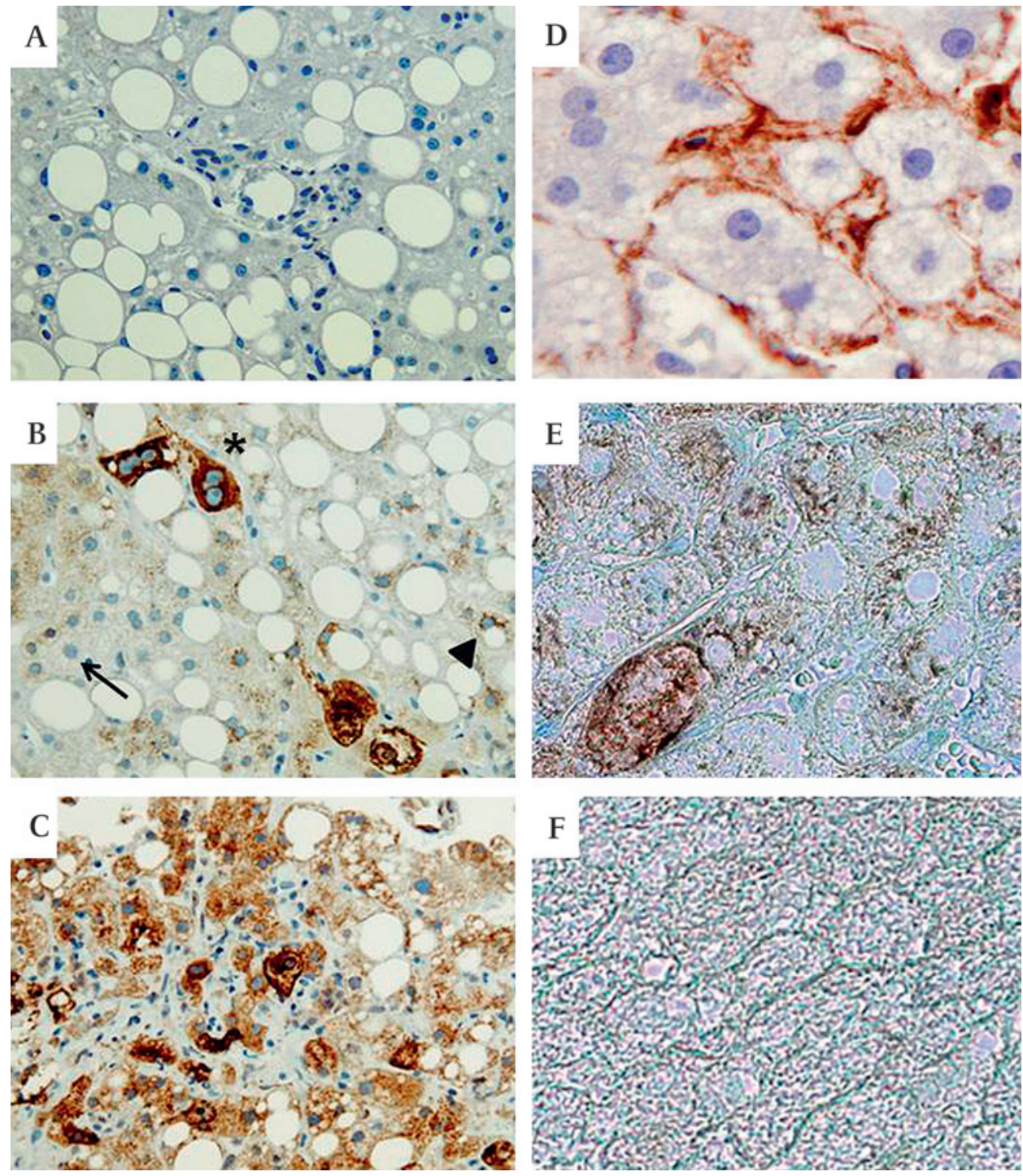

that were surrounded by stromal cells that expressed the myofibroblast marker, $\alpha$-SMA. Double-immunostaining for Shh (brown) and $\alpha$-SMA (blue) confirmed that $\alpha$-SMA-positive myofibroblastic cells tended to localise near regions of Shhexpressing hepatocytes within the hepatic parenchyma (figure 8D,E). Thus, in NASH, a type of human liver disease in which there is increased hepatocyte apoptosis, increased hepatocyte expression of Hh ligands occurs, and this is accompanied by evidence of HSC activation and increased fibrogenesis.

\section{DISCUSSION}

Our results in $\operatorname{lkk} \beta^{\Delta \mathrm{Hep}}$ mice, a murine model of increased hepatocyte death, demonstrate that optimal viability and proliferative capacities of mature hepatocytes are heavily dependent upon an intact NF- $\mathrm{B}$ pathway, whereas Hh signalling in liver progenitors provides an alternative survival mechanism that permits them to survive and proliferate even when NF- $\kappa \mathrm{B}$ nuclear localisation is impaired. Moreover, we discovered that when the Ikk $\beta-N F-k B$ pathway is disrupted in mature hepatocytes, they produce $\mathrm{Hh}$ ligands. This enriches the hepatic microenvironment with factors that enhance the growth of Ikk $\beta$-deficient progenitor cells. As these progenitors mature, they eventually lose the ability to transduce Hh-initiated signals, and become more reliant on NF- $\kappa$ B-regulated viability factors. Thus, their vulnerability to apoptosis increases because Ikk $\beta-N F-\kappa B$ signalling has been disrupted, and this perpetuates the increased rate of mature hepatocyte apoptosis. The latter maintains heightened production of $\mathrm{Hh}$ ligands and stimulates the continued outgrowth of Hh-responsive non-parenchymal cells that rely on Hh signalling to survive, including myofibroblasts. Progressive hepatic accumulation of such cells promotes fibrogenic repair, helping to explain why liver fibrosis is increased in $\operatorname{Ikk} \beta^{\Delta \mathrm{Hep}}$ mice.

Increased hepatocyte production of Hh ligands and accumulation of Hh target cells (ie, MF cells) were also demonstrated in patients with NASH. Increased rates of hepatocyte apoptosis are known to occur in this common type of chronic human liver disease. Moreover, hepatic apoptotic activity predicts the severity of liver fibrosis in NASH, and is significantly greater in patients with advanced fibrosis than in patients with early fibrosis. ${ }^{20}$ MF-HSCs play major roles in excessive matrix accumulation during many types of chronic liver disease, including NASH. Earlier work showed that phagocytosis of apoptotic bodies activates quiescent HSCs (Q-HSCs) to become MFHSCs. ${ }^{21}$ Therefore, the early stages of fibrosis in NASH are characterised by deposition of fibrous matrix around hepatocytes and along sinusoids. ${ }^{22}$

The new evidence that injured hepatocytes in NASH produce Shh ligands provides another mechanism that helps to explain the pattern of liver fibrosis that occurs in NASH because HSCs 
are capable of responding to Hh ligands. In healthy livers, Q-HSCs produce relatively large amounts of Hip (Hh-interacting protein), a potent Hh ligand antagonist. However, HSC expression of Hip is abolished by liver injury (or culture), permitting Hh-dependent induction of MF genes and enhancing the viability and proliferative activity of MF-HSCs. ${ }^{18}{ }^{19}$ MF-HSCs themselves produce and release Hh ligands, ${ }^{19}$ further enriching the hepatic microenvironment with these factors.

Mature Hh ligands diffuse away from the cells that produce them, and variably modulate gene expression in distant Hhresponsive cells. Target cell effects depend upon the concentration and duration of $\mathrm{Hh}$ ligand exposure. ${ }^{23}$ Membranous particles containing biologically active $\mathrm{Hh}$ ligands have been purified from the blood and bile of experimental animals with liver injury, ${ }^{17}$ suggesting routes by which Hh ligands generated by apoptotic hepatocytes and MF-HSCs might be disseminated both extrahepatically and to other parts of the liver lobule. Hepatic progenitors that reside in the canals of Hering and bile ductular cells in PTs are Hh responsive, and Hh ligands released from MFHSCs have been shown to enhance the viability and proliferative activity of both cell types. ${ }^{24}$ This promotes the ductular response that often accompanies chronic liver injury. ${ }^{24} 25 \mathrm{Hh}$ ligands also stimulate immature ductular cells to undergo epithelial to mesenchymal transition (EMT), ${ }^{26}$ a process that may furher contribute to liver fibrosis. ${ }^{26}$ Indeed, quantitiative reverse transcription-PCR (RT-PCR) analysis of liver RNA from Ikk $\beta^{\Delta \text { Hep }}$ mice demonstrated increased expression of various EMT-related factors (Supplementary figure 4). Hence, evidence that dying hepatocytes release morphogens that trigger hepatic accumulation of cell types that mediate fibrogenic repair suggests a unifying mechanism that helps to explain the strong association between chronic liver injury and fibrogenesis. This discovery identifies novel diagnostic and therapeutic targets for further research that are relevant to various types of chronic liver injury.

Acknowledgements We like to thank Dr Michael Karin (University of California, San Diego) for providing the Ikk ${ }^{\mathrm{F} / F}$ and Ikk ${ }^{\Delta H E P}$ mice and helpful discussion.

Funding This work was supported by NIH grant 5R01-DK077794 to AMD.

Competing interests None.

Ethics approval This study was conducted with the approval of the Duke University, Division of Gastroenterology and Department of Pathology, Duke University School of Medicine Tissue Bank Shared Resource.

Provenance and peer review Not commissioned; externally peer reviewed.

\section{REFERENCES}

1. Henderson NC, Forbes SJ. Hepatic fibrogenesis: from within and outwith. Toxicology 2008;254:130-5.

2. Michalopoulos GK, DeFrances MC. Liver regeneration. Science 1997;276:60-6.
3. Hacker H, Karin M. Regulation and function of IKK and IKK-related kinases. Sci STKE;2006:re13.

4. Cosulich SC, James NH, Needham MR, et al. A dominant negative form of IKK2 prevents suppression of apoptosis by the peroxisome proliferator nafenopin. Carcinogenesis 2000;21:1757-60.

5. Li ZW, Chu W, Hu Y, et al. The IKKbeta subunit of IkappaB kinase (IKK) is essential for nuclear factor kappaB activation and prevention of apoptosis. J Exp Med 1999; 189:1839-45

6. Schwabe RF, Bennett BL, Manning AM, et al. Differential role of I kappa B kinase 1 and 2 in primary rat hepatocytes. Hepatology 2001;33:81-90

7. Sicklick JK, Li YX, Choi SS, et al. Role for hedgehog signaling in hepatic stellate cell activation and viability. Lab Invest 2005:85:1368-80.

8. Sicklick JK, Li YX, Melhem A, et al. Hedgehog signaling maintains resident hepatic progenitors throughout life. Am J Physiol Gastrointest Liver Physiol 2006:290:G859-70.

9. Maeda S, Chang L, Li ZW, et al. IKKbeta is required for prevention of apoptosis mediated by cell-bound but not by circulating TNFalpha. Immunity 2003;19:725-37.

10. Seglen PO. Hepatocyte suspensions and cultures as tools in experimental carcinogenesis. J Toxicol Environ Health 1979;5:551-60.

11. Petersen BE, Grossbard B, Hatch $\mathrm{H}$, et al. Mouse A6-positive hepatic oval cells also express several hematopoietic stem cell markers. Hepatology 2003;37:632-40.

12. Deng J, Steindler DA, Laywell ED, et al. Neural trans-differentiation potential of hepatic oval cells in the neonatal mouse brain. Exp Neurol 2003;182:373-82.

13. Hixson DC, Allison JP. Monoclonal antibodies recognizing oval cells induced in the liver of rats by $\mathrm{N}$-2-fluorenylacetamide or ethionine in a choline-deficient diet. Cancer Res 1985:45:3750-60.

14. Roskams T, Yang SQ, Koteish A, et al. Oxidative stress and oval cell accumulation in mice and humans with alcoholic and nonalcoholic fatty liver disease. Am J Pathol 2003; 163:1301-11.

15. Varjosalo M, Taipale J. Hedgehog: functions and mechanisms. Genes Dev 2008:22:2454-72.

16. Omenetti A, Popov $Y$, Jung $Y$, et al. The hedgehog pathway regulates remodelling responses to biliary obstruction in rats. Gut 2008;57:1275-82.

17. Witek RP, Yang L, Liu R, et al. Liver cell-derived microparticles activate hedgehog signaling and alter gene expression in hepatic endothelial cells. Gastroenterology 2009; 136:320-30.

18. Choi SS, Omenetti A, Witek RP, et al. Hedgehog pathway activation and epithelialto-mesenchymal transitions during myofibroblastic transformation of rat hepatic cells in culture and cirrhosis. Am J Physiol Gastrointest Liver Physio 2009;297:1093-106

19. Yang L, Wang $\mathrm{Y}$, Mao $\mathrm{H}$, et al. Sonic hedgehog is an autocrine viability factor for myofibroblastic hepatic stellate cells. J Hepatol 2008;48:98-106.

20. Feldstein AE, Wieckowska A, Lopez AR, et al. Cytokeratin-18 fragment levels as noninvasive biomarkers for nonalcoholic steatohepatitis: a multicenter validation study. Hepatology 2009:50:1072-8.

21. Canbay A, Feldstein AE, Higuchi $H$, et al. Kupffer cell engulfment of apoptotic bodies stimulates death ligand and cytokine expression. Hepatology 2003;38:1188-98.

22. Brunt EM. Pathology of nonalcoholic steatohepatitis. Hepatol Res 2005; 33:68-71.

23. Jeong J, McMahon AP. Cholesterol modification of hedgehog family proteins. J Clin Invest 2002;110:591-6.

24. Omenetti A, Yang L, Li YX, et al. Hedgehog-mediated mesenchymal-epithelial interactions modulate hepatic response to bile duct ligation. Lab Invest 2007:87:499-514.

25. Richardson MM, Jonsson JR, Powell EE, et al. Progressive fibrosis in nonalcoholic steatohepatitis: association with altered regeneration and a ductular reaction. Gastroenterology 2007:133:80-90.

26. Omenetti A, Porrello A, Jung $Y$, et al. Hedgehog signaling regulates epithelialmesenchymal transition during biliary fibrosis in rodents and humans. J Clin Invest 2008:118:3331-42. 